\title{
Distribution pattern of psoriasis, anxiety and depression as possible causes of sexual dysfunction in patients with moderate to severe psoriasis*
}

\author{
Alejandro Molina-Leyva ${ }^{1,2}$ \\ Jose Carlos-Ruiz Carrascosa ${ }^{1}$ \\ Ramon Naranjo-Sintes ${ }^{1}$
}

\author{
Ana Almodovar-Real ${ }^{1}$ \\ Ignacio Molina-Leyva ${ }^{1}$ \\ Jose Juan Jimenez-Moleon ${ }^{3}$
}

DOI: http:/ / dx.doi.org/10.1590/abd1806-4841.20153254

\begin{abstract}
A bstract: BACKGROUND: Psoriasis may significantly impair sexual function. Depression and organic factors appear to play a key role in this relation. However, beyond genital psoriasis, the importance of the disease's distribution patterns has not been considered.

Овјестіves: To research sexual function in psoriasis patients and investigate the roles of anxiety, depression and psoriasis' distribution patterns in sexual dysfunction.

Methods: A comparative study matched for sex and age was performed. Eighty patients with moderate to severe psoriasis and 80 healthy controls were included. The participants completed the Massachusetts General HospitalSexual Functioning Questionnaire, the Hospital Anxiety and Depression Scale, and the Self-Administered Psoriasis Area and Severity Index.

RESUlTS: Psoriasis was associated with sexual dysfunction, odds ratio=5.5 (CI 95\% 2.6-11.3; $\mathrm{p}<0.001)$. Certain distribution patterns of psoriasis, involving specific body regions, were associated with an increase in sexual dysfunction in the group presenting the disease, odds ratio 7.9 (CI 95\% 2.3-33.4; $\mathrm{p}<0.001$ ). Multivariate logistic regression analysis identified anxiety and depression, and the involvement of these specific areas, as possible independent risk factors for sexual dysfunction in patients with moderate to severe psoriasis.

CONCLUSION: This study identifies body areas potentially related to sexual dysfunction, independently of anxiety and depression, in psoriasis patients. The results suggest that the assessment of sexual dysfunction and the involvement of these body areas should be considered as disease severity criteria when choosing the treatment for psoriasis patients.
\end{abstract}

Keywords: Anxiety; Case-control studies; Depression; Psoriasis; Sexual dysfunctions, psychological

\section{INTRODUCTION}

Psoriasis is a chronic, inflammatory cutaneous disease with a worldwide estimated prevalence ranging from 0.9 to $8.5 \% .{ }^{1}$ Its impact upon patient's quality of life is striking, with social and psychological consequences comparable to those of other illnesses such as cancer, heart diseases or diabetes mellitus. ${ }^{2,3}$ Psoriasis has been associated with different psychological problems, including low self-esteem, depression, anxiety, sexual dysfunction, or suicide ideation. ${ }^{4-6}$ According to the World Health Organization (WHO), sexuality is a basic need and an element that cannot be separat- ed from other aspects of human life, being extremely important for maintaining good mental health. ${ }^{7}$ The impact of psoriasis upon sexual function seems to be substantial, and it can result in significant alterations in quality of life. ${ }^{8-11}$ The hypotheses proposed to explain such an increase in sexual dysfunction have taken into consideration the severity of the disease, and psychological and physical comorbidities associated to psoriasis. ${ }^{12}$ Psoriasis is correlated with marked stigmatization regarding body image changes. ${ }^{6,9}$ However, with the exception of the genital area, we have not

Received on 07.01.2013

Approved by the Advisory Board and accepted for publication on 18.06.2014

Work performed at the University Hospital, Granada- Granada, Spain.

Financial Support: None.

Conflict of Interest: None.

Granada University Hospital. University of Granada - Granada, Spain

Torrecardenas Hospital- Almeria, Spain.

CIBER de Epidemiología y Salud Pública (CIBERESP), Spain.

C2015 by Anais Brasileiros de Dermatologia 
found any studies on the impact of psoriatic lesions' distribution patterns upon sexual function. The present study evaluates and compares sexual function in patients with moderate to severe psoriasis versus a healthy population. Moreover, we have investigated the influence of depression or anxiety and psoriasis' distribution patterns upon sexual function.

\section{METHODS}

\section{Design and study population}

A prospective case series study with patients diagnosed with moderate to severe psoriasis was conducted between November $1^{\text {st }} 2012$ and February $1^{\text {st }}$ 2013. Severity was assessed according to a consensus document of the Spanish Academy of Dermatology. ${ }^{13}$ The study sample was recruited among the patients attending their scheduled follow-up visits to the psoriasis unit at the Granada University Hospital. A healthy volunteer, without the dermatological disease and matched for sex and age ( \pm 5 years) to each selected psoriasis case, was recruited among those accompanying the dermatological and pediatric patients in the Dermatology and Pediatric clinics' shared waiting room. The study was approved by the Ethic Committee of the Granada University Hospital.

Selection criteria were assessed through personal interview, and those who fulfilled the criteria were invited to participate in the study. Inclusion criteria were: being 18 years of age or older and sexually active. Exclusion criteria were: refusal to participate in the study, active dermatological diseases other than psoriasis, treatment with psychotropic drugs and other drugs well known to interfere with sexual function, intellectual disabilities, and active malignant diseases. All participants gave written informed consent to participate in the study. The participants completed a self-administered questionnaire (identified by code only). They filled it out by themselves in a quiet room. After completing the questionnaire, it was placed in a special container, and the participants could leave the hospital without seeing the medical staff again.

\section{formation}

\section{Main endpoints of interest and sources of in-}

Socio-demographic data and biometric parameters were collected through clinical interview and physical examination. Three physical comorbidities were considered in the analysis: hypertension, dyslipidemia, and diabetes mellitus. Diagnoses were acknowledged when the patients received active treatment for the disorders. In patients with psoriasis, severity was assessed calculating the body surface area affected by the disease (BSA), and using the Psoriasis Area and Severity Index (PASI). ${ }^{14}$ PASI is obtained by weighting the affected body surface area to the degree of desquamation, erythema and induration in different body regions. The following were considered as treatments: methotrexate, cyclosporine and acitretin categorized as classical systemic drugs; and infliximab, etanercept, adalimumab and ustekinumab categorized as biological drugs.

The main variables were the presence of sexual dysfunction, problems of anxiety and/or depression, and psoriasis' distribution patterns. The Massachusetts General Hospital-Sexual Functioning Questionnaire (MGH-SFQ) was used to assess sexual function. ${ }^{15}$ The MGH-SFQ is a self-administered questionnaire designed to detect sexual dysfunction, and has been validated in the Spanish population. ${ }^{16}$ The questionnaire comprises 5 items addressing the different phases of the sexual cycle: sexual interest, excitation, orgasm, erection (only in males), and global sexual satisfaction. Each item is scored from 0 (completely reduced) to 4 (normal). High scores indicate better sexual functioning. Sexual dysfunction is considered when at least one item yields a score less than 4 . The prevalence of sexual dysfunction was estimated for psoriasis patients and healthy volunteers.

The Hospital Anxiety and Depression Scale (HADS) was used to evaluate the anxiety and depression levels. ${ }^{17}$ HADS is a self-administered questionnaire designed to assess anxiety and depression disorders, and has also been validated in the Spanish population. ${ }^{18}$ The questionnaire consists of 14 items divided into two scales of 7 items each. A 4-point Likert scale, ranging from 0 to 3 , evaluates the strength of the symptom. Subscale scores higher than 7 indicated signs of anxiety or depression, and scores higher than 10 suggested a clinical problem. The prevalence of anxiety and depression was estimated by using these cut-offs. The human diagram of the Self Administered Psoriasis Area and Severity Index (SAPASI) was used to assess the distribution pattern of psoriatic lesions. ${ }^{19}$ Data from the diagram was coded into 22 body areas. Considering the prevalence of sexual dysfunction in the overall population - described subsequently- a sample with 80 psoriatic patients plus 80 healthy volunteers would achieve a power higher than $80 \%$ to detect differences equal to or higher than 20 points in the aforesaid prevalence between patients with psoriasis and the general population, with an alpha=0.05.

\section{D ata analysis}

Descriptive statistics were used to explore the characteristics of the two groups, comparing those with psoriasis versus the control group. Continuous data were expressed as the mean and standard deviation (SD). The absolute and relative frequency distributions were estimated for qualitative variables. MannWhitney Utest was performed to compare quan- 
titative data between psoriasis patients and healthy volunteers. The $\chi 2$ test or when necessary, the Fisher exact test were used for qualitative variables. Significance was set at $p<0.05$. Crude and adjusted odds ratios (OR), as well as confidence intervals (CI 95\%) were computed by logistic regression models, to explore factors associated with sexual dysfunction. The main outcome of interest, sexual dysfunction, was binary codified as either sexual dysfunction (MGH-SFQ score less than 20 for males and less than 16 for females) or no sexual dysfunction (MGH-SFQ score $=20$ for males and $=16$ for females). ${ }^{16}$ Epidemiological and statistical criteria were used to model variable selection. ${ }^{20,21}$ The effect of each exploratory variable in the model and its significance was studied. If the variable improved the model fit and adequacy (based on the likelihood ratio criteria and the significance of the parameter) it was kept; otherwise, the variable was excluded. Different models were fitted with respect to the factors related to sexual dysfunction and psoriasis. The model was checked for pair-wise interaction between covariates. Interactions with sex and age were considered. Potential confounding covariates were studied using a significance change of the parameters in the model or a change of $30 \%$ of its value. ${ }^{22}$ Once the model was fitted to the data, the adequacy of fit was assessed by the Hosmer-Lemeshow test. A sub-analysis was conducted to explore the impact of psoriasis' distribution patterns on sexual function in patients with the disease. Analyses were performed using the Stata statistical software (version 11.0).

\section{RESULTS}

A total of 95 patients with moderate to severe psoriasis were invited to join the study. Four of these patients had intellectual disabilities, and were thus excluded. Five patients undergoing treatment for depression and one patient with psychotic disorder were also excluded. Five patients decided not to participate, citing lack of time to complete the questionnaire. In turn, 88 healthy controls matched for age and sex were invited to participate. Two controls were in treatment for depression and were excluded. Six of the controls decided not to participate, citing a lack of time. The study was therefore carried out on 80 psoriasis patients and 80 healthy controls. Table 1 summarizes the socio-demographic characteristics of those participating in the study. Both groups were comparable in terms of age, sex, educational level, marital status and occupation. Table 2 shows the clinical features of patients with psoriasis.

The results of the MGH-SFQ are summarized in table 3. Compared to controls, the psoriasis group showed significant impairment of all the components of sexual function. "Sexual interest" and "global sexual satisfaction" were the most negatively affected components. Male patients with psoriasis showed an increase in erectile dysfunction compared to controls. The prevalence of sexual dysfunction was $53.7 \%$ in patients with psoriasis vs. $17.5 \%$ in healthy volunteers $(p<0.001)$. The frequency of sexual dysfunction, in the crude analysis, was higher in psoriasis patients compared to controls, 5.5 (CI 95\% 2.6-11.3; p<0.001). A sub

TABLE 1: Socio-demographic characteristics of the participants. (Granada University Hospital, 2012-2013)

\begin{tabular}{|c|c|c|c|}
\hline & $\begin{array}{l}\text { Healthy volunteer } \\
(n=80)\end{array}$ & Psoriasis $(n=80)$ & p-values \\
\hline Age (years) & $41.0 \pm 13.1$ & $43.4 \pm 12.7$ & 0.225 \\
\hline Male: female ratio & $1: 1$ & $1: 1$ & 1.000 \\
\hline M arital status (\%) & & & 0.675 \\
\hline Single & $20(25.0)$ & $18(22.5)$ & \\
\hline Married & $58(72.5)$ & $58(72.5)$ & \\
\hline Other & $2(2.5)$ & $4(4.9)$ & \\
\hline Educational level (\%) & & & 0.797 \\
\hline Primary incomplete & $26(32.5)$ & $30(37.5)$ & \\
\hline Secondary & $21(26.3)$ & $20(25)$ & \\
\hline Academic & $33(41.2)$ & $30(37.5)$ & \\
\hline Employment status (\%) & & & 0.341 \\
\hline Employed & $46(57.5)$ & $40(50.0)$ & \\
\hline Unemployed & $34(42.5)$ & $40(50.0)$ & \\
\hline Place of residence $(\%)$ & & & 0.409 \\
\hline Urban & $54(67.5)$ & $49(61.2)$ & \\
\hline Rural & $26(32.5)$ & $31(38.8)$ & \\
\hline BMI & $24.1 \pm 3.2$ & $28.2 \pm 6.7$ & $<0.001^{*}$ \\
\hline Smoking & $4(4.9)$ & $26(32.5)$ & $<0.001^{*}$ \\
\hline Arterial hypertension & $10(12.5)$ & $19(23.7)$ & 0.065 \\
\hline Dyslipidemia & $3(3.7)$ & $9(11.2)$ & 0.071 \\
\hline Diabetes mellitus & $1(1.2)$ & $5(6.2)$ & 0.096 \\
\hline
\end{tabular}

Data are expressed as mean \pm standard deviation and as number (percentage) BMI: body mass index. * p-values $<0.05$ were considered statistically significant 
analysis including drugs for psoriasis treatment was performed. No association between drugs for psoriasis treatment and sexual dysfunction was found.

The results of the HADS are shown in table 3. The frequency of anxiety signs, considering a cut-off score above 7 , was higher in patients with psoriasis than in the overall population, $50 \%$ vs. $20 \%$ respectively, OR 4.0 (CI 95\% 1.9 - 8.0; $\mathrm{p}<0.001$ ). The same was observed for signs of depression. Although the absolute magnitude was lower than that of anxiety, 32.5\% vs. $4.9 \%$ for psoriasis patients and healthy volunteers respectively, the relative magnitude of the association was higher, OR 9.1 (CI 95\% 3.0 - 27.7; $\mathrm{p}<0.001$ ). Since nearly all the subjects with signs of depression also presented signs of anxiety, a new variable, "signs/evidence of anxiety and/or depression", which included

TABLE 2: Characteristics of psoriasis patients. (Granada University Hospital, 2012-2013)

\begin{tabular}{ll}
\hline & $(\mathrm{n}=80)$ \\
\hline PASI & $2.7(1.2 \sim 7.1)$ \\
BSA & $4.0(1.6 \sim 15.0)$ \\
Nail involvement & $31(38.7)$ \\
Psoriatic arthritis & $24(30)$ \\
Age at onset & $22(13 \sim 38)$ \\
Years of evolution & $9(3 \sim 27)$ \\
Psoriasis treatment & $14(17.5)$ \\
Topical & $27(33.7)$ \\
Classical systemic drugs & $39(48.7)$ \\
Biologic drugs &
\end{tabular}

Data are expressed as median (percentile 25 percentile 75 ) and as number (percentage). BSA: body surface area affected by psoriasis. PASI: Psoriasis Area and Severity Index. all the subjects with a cut-off score higher than 7 on the HADS anxiety subscale or HADS depression subscale, was coded. Therefore, there seemed to be a co-relation between psoriasis, signs of anxiety and/or depression and sexual dysfunction. Table 4 shows the factors associated with sexual dysfunction. After adjusting for signs of anxiety and/or depression, the observed association between psoriasis and sexual dysfunction remained significant, adjusted OR 2.9 (CI 95\% 1.2- 7.0; p=0.016)

After coding the results of the SAPASI body diagram in the psoriasis group, the ventral regions of legs/shins were found to be the most frequently affected body area $(56.2 \%)$, and $18.7 \%$ of the patients showed involvement of the genital area. The association between the different body areas and sexual dysfunction is summarized in table 5. Psoriasis lesions on the genitals, buttocks, abdomen or lumbar region were significantly linked to sexual dysfunction. A new variable, which included all patients with psoriasis lesions in any of these Areas of Sexual Impact (ASI), was coded. Figure 1 represents the distribution and frequency of lesions in psoriasis patients with sexual dysfunction. Psoriasis patients with ASI involvement showed a 7.9-fold higher risk of developing sexual dysfunction than psoriasis patients without it - adjusted OR 7.9 (CI $95 \% 2.3-33.4 ; \mathrm{p}<0.001)$. Finally a sub-analysis including only the patients without ASI involvement was conducted. The results showed that psoriasis patients without ASI involvement did not have a greater risk of sexual dysfunction than controls, adjusted OR 1.1 (CI $95 \% 0.3-3.8 ; \mathrm{p}=0.873)$.

TABLE 3: Results of the Massachusetts General Hospital-Sexual Functioning Questionnaire (MGH-SFQ) and of the Hospital Anxiety and Depression Scale (HADS). (Granada University Hospital, 2012-2013)

\begin{tabular}{|c|c|c|c|}
\hline MGH-SFQ & Controls & Psoriasis & p-values \\
\hline Sexual interest & $3.7 \pm 0.8$ & $2.9 \pm 1.4$ & $<0.001$ \\
\hline Sexual arousal & $3.8 \pm 0.8$ & $3.0 \pm 1.3$ & $<0.001$ \\
\hline Orgasm & $3.7 \pm 0.8$ & $3.1 \pm 1.3$ & $<0.001$ \\
\hline Erection (only male) & $3.9 \pm 0.2$ & $3.2 \pm 1.1$ & $<0.001$ \\
\hline Global sexual satisfaction & $3.6 \pm 0.9$ & $2.9 \pm 1.4$ & $<0.001$ \\
\hline Total score male & $19.3 \pm 3.2$ & $16.2 \pm 5.3$ & 0.002 \\
\hline Total score female & $14.6 \pm 3.9$ & $11.2 \pm 5.6$ & 0.002 \\
\hline Individuals with sexual dysfunction (\%) & $14(17.5)$ & $43(53.7)$ & $<0.001$ \\
\hline HADS & Controls & Psoriasis & p-values \\
\hline Signs of anxiety (HADS-A 8 8 ) & $16(20.0)$ & $40(50.0)$ & $<0.001$ \\
\hline Signs of depression (HADS-D $8 \leq$ ) & $4(4.9)$ & $26(32.5)$ & $<0.001$ \\
\hline $\begin{array}{l}\text { Signs of anxiety and/or depression } \\
\text { (HADS-D } 8 \leq \text { and/or HADS-A } 8 \leq \text { ) }\end{array}$ & $17(21.5)$ & $43(53.7)$ & $<0.001$ \\
\hline
\end{tabular}

Data are expressed as mean \pm standard deviation and as percentage (number). MGH-SFQ: Each item is scored from 0 (completely reduced) to 4 (normal). Sexual dysfunction: score less than 20 for males and less than 16 for females. HADS-A: anxiety subscale. HADS-D: depression subscale. 
TABLE 4: Univariate and multivariate logistic regression analysis of potential factors linked to sexual dysfunction.

(Granada University Hospital, 2012-2013)

\begin{tabular}{|c|c|c|c|c|}
\hline & Univariate analysis & p-value & M ultivariate analysis & p-value \\
\hline & \multicolumn{2}{|l|}{ Unadjusted OR } & \multicolumn{2}{|l|}{ Adjusted OR } \\
\hline Psoriasis & $5.5(2.6-11.3)$ & $<0.001^{*}$ & $2.9(1.2-7.0)$ & $0.016^{*}$ \\
\hline Age & $1.0(0.9-1.1)$ & 0.609 & $1.0(0.9-1.1)$ & 0.992 \\
\hline Sex & $0.5(0.3-1.1)$ & 0.069 & $0.5(0.2-1.1)$ & 0.080 \\
\hline $\mathrm{BMI}>25 \mathrm{~kg} / \mathrm{m} 2$ & $1.7(0.9-3.4)$ & 0.095 & $0.9(0.4-2.2)$ & 0.823 \\
\hline Smoking & $6.1(2.5-14.6)$ & $<0.001^{*}$ & $5.0(1.8-15.0)$ & $0.001^{*}$ \\
\hline Arterial hypertension & $3.7(1.6-8.8)$ & $0.002^{*}$ & $5.4(1.8-17.2)$ & $0.002^{*}$ \\
\hline Dyslipidemia & $2.6(0.8-9.3)$ & 0.096 & $2.8(0.4-18.4)$ & 0.228 \\
\hline Diabetes mellitus & $1.8(0.3-10.3)$ & 0.463 & $0.3(0.1-3.4)$ & 0.379 \\
\hline Signs of anxiety and/or depression & $3.9(1.9-7.7)$ & $<0.001^{*}$ & $3.5(1.5-8.2)$ & $0.003^{*}$ \\
\hline
\end{tabular}

* p-values < 0.05 were considered statistically significant. BMI: body mass index. Adjustment variables: psoriasis, sex, BMI > 25 kg/m2, smoking, arterial hypertension, dyslipidemia, diabetes mellitus, signs of anxiety and/or depression.

TAвle 5: Psoriatic lesions' distribution patterns and associated sexual dysfunction.

(Granada University Hospital, 2012-2013)

\begin{tabular}{|c|c|c|c|c|}
\hline & $\begin{array}{l}\text { Subjects with } \\
\text { lesions on these areas }\end{array}$ & $\begin{array}{l}\text { Sexual dysfunction with } \\
\text { lesions on these areas }\end{array}$ & $\begin{array}{l}\text { Sexual dysfunction without } \\
\text { lesions on these areas }\end{array}$ & p-values \\
\hline Face & $10(12.5)$ & $5(50.0)$ & $38(54.2)$ & 0.065 \\
\hline Chest & $25(31.2)$ & $16(64.0)$ & $27(49.0)$ & 0.215 \\
\hline Abdomen & $34(42.5)$ & $23(67.6)$ & $20(43.4)$ & $0.032^{*}$ \\
\hline Genitals & $15(18.7)$ & $13(86.6)$ & $30(46.1)$ & $0.002^{*}$ \\
\hline Arms & $14(17.5)$ & $10(71.3)$ & $33(50.0)$ & 0.144 \\
\hline Forearms (ventral surface) & $25(31.2)$ & $14(56.0)$ & $29(52.7)$ & 0.785 \\
\hline Palms & $14(17.5)$ & $9(64.2)$ & $34(51.5)$ & 0.384 \\
\hline Thighs & $23(28.7)$ & $16(69.5)$ & $27(47.3)$ & 0.071 \\
\hline Knees & $27(33.7)$ & $16(59.2)$ & $27(50.9)$ & 0.480 \\
\hline Shins/Legs & $45(56.2)$ & $23(51.1)$ & $20(57.1)$ & 0.591 \\
\hline Foot (dorsal surface) & $12(15.0)$ & $8(66.6)$ & $35(51.4)$ & 0.330 \\
\hline Scalp & $34(42.5)$ & $21(61.7)$ & $22(47.8)$ & 0.216 \\
\hline Dorsal region & $18(22.5)$ & $11(61.1)$ & $32(51.6)$ & 0.467 \\
\hline Lumbar region & $31(38.7)$ & $21(67.7)$ & $22(44.9)$ & $0.046^{*}$ \\
\hline Arms (dorsal surface) & $14(17.5)$ & $10(71.4)$ & $33(50.0)$ & 0.144 \\
\hline Elbow & $41(51.2)$ & $24(58.5)$ & $19(48.7)$ & 0.378 \\
\hline Forearm (dorsal surface) & $21(26.5)$ & $13(61.9)$ & $30(50.8)$ & 0.383 \\
\hline Hand (dorsal surface) & $15(18.9)$ & $9(60.0)$ & $34(53.1)$ & 0.592 \\
\hline Buttocks & $29(36.2)$ & $22(75.8)$ & $21(41.1)$ & $0.002^{*}$ \\
\hline Femoral region & $28(35.0)$ & $18(64.2)$ & $25(48.0)$ & 0.165 \\
\hline Soleus region & $34(42.5)$ & $19(55.8)$ & $24(52.1)$ & 0.742 \\
\hline Sole of the foot & $10(12.5)$ & $8(80.0)$ & $35(50.0)$ & 0.075 \\
\hline ASI & $35(56.2)$ & $31(68.8)$ & $12(34.2)$ & $0.001^{*}$ \\
\hline
\end{tabular}

* P-values < 0.05 were considered statistically significant. ASI: Areas of Sexual Interest

\section{DISCUSSION}

To our knowledge, this is the largest prospective analytical study on sexual dysfunction in patients with moderate to severe psoriasis using a validated and specific measurement tool to assess sexual function, and the first to broadly explore the impact of psoriatic lesions' distribution patterns on sexual function. The results of our study show a meaningful clinical association between moderate to severe psoriasis and sexual dysfunction. The human sexual response cycle is complex. Certain components of sexual response, such as sexual interest, depend primarily on psychological factors, and are impaired by conditions such as anxiety and depression, while others such as erection and orgasm can be affected by psychological and physical causes. ${ }^{23,24}$ Sexual impairment in psoriasis patients occurs in all components of the sexual response. This suggests that sexual dysfunction in psoriasis must be a consequence of several combined factors. 


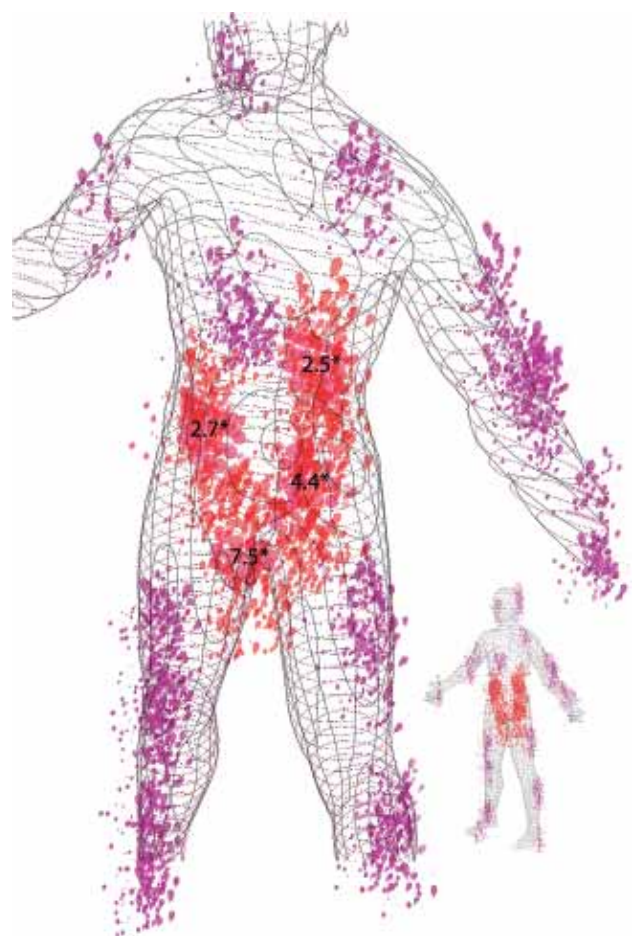

FIGURE 1: Tridimensional parametric representation of areas of sexual interest (ASI). The amount of lesions in the body diagram represents the proportion of psoriasis patients with involvement of these areas, which have sexual dysfunction. ASI areas appear highlighted in red. *Odds ratio between the involvement of each ASI component (abdomen, genitals, buttocks and lumbar area) and sexual dysfunction

Few studies have been published in the field of sexual dysfunction in psoriasis and its possible causes. ${ }^{12}$ The main causal hypotheses have focused on the role of psychological morbidities. All the studies that evaluated psychological factors have proposed depression as a key link between psoriasis and sexual dysfunction. ${ }^{10,25-27}$ The prevalence of sexual dysfunction in psoriasis patients in our study coincides with previous reports. ${ }^{9,12,27}$ In agreement with prior studies, we observed that depression is likely of great importance in the causal relationship between psoriasis and sexual dysfunction, because of its increased prevalence in this population. Consistent with the available scientific evidence, psoriasis patients with signs of depression had a higher risk of sexual dysfunction compared with psoriatic patients without such problems ${ }^{12}$. In our study we have considered anxiety, which is also connected to sexual dysfunction and psoriasis, and have chosen a low cut-off score for anxiety and depression in the analysis in order to include all subjects with psychological impairment and comprehensively characterize the role of a psychological linking factor between psoriasis and sexual dysfunction. ${ }^{28,29}$ How- ever, even after expanding the range of psychological conditions and performing an adjusted analysis, the association between psoriasis and sexual dysfunction remained clinically and statistically significant. Consequently, the aforementioned factor would not be the only element implied in this relationship.

Furthermore, psoriasis itself may play an important role on sexual dysfunction development in these patients. In this sense, patients with involvement of ASI areas, frequently affected by psoriasis and co-related with important stigmatization, are more likely to suffer sexual dysfunction than patients that are free of lesions in these areas ${ }^{30,31}$ figure 1 . This association was independent of anxiety or depression levels, and these areas were thus referred to areas of sexual impact (ASI). Physiological and pathological changes in body image, such as pregnancy or surgical sequelae, have been linked to sexual dysfunction through the impairment of self-esteem and sexual distress. ${ }^{32-34} \mathrm{Un}$ expectedly, studies that offer an in-depth analysis on the repercussion of body image changes in dermatological diseases and their impact on sexual function are scarce - particularly considering that changes in body image are virtually constant in cutaneous diseases. ${ }^{7,9,35}$ Psoriasis implies obvious changes in body image in the form of visible and touchable lesions that can affect any corporal area. Psoriasis lesions can affect visible body regions, and the involvement of such areas has been linked to greatly impaired quality of life and prominent interference in social relationships. Such lesions are therefore regarded as severity criteria in deciding the therapeutic approach. ${ }^{13,36,37}$ Sexual dysfunction secondary to psoriasis affecting ASI could probably be facilitated by feelings of stigmatization, shame, low self-esteem and increased sexual distress. ${ }^{38-40}$ These feelings would arise specifically during sexual activity, and consequently sexual dysfunction linked to ASI involvement is independent of the psychological state in terms of anxiety or depression. We conducted a sub-analysis including only patients without ASI involvement, which showed sexual function to be similar to that of the control group when ASI areas were not affected by psoriasis lesions. Thus, the presence of signs of anxiety and/or depression and ASI involvement could be considered as possible risk factors in the link between psoriasis and sexual dysfunction.

We acknowledge some methodological weakness in our study: 1) The cross-sectional character of the study. We have included prevalent cases of psoriasis in the analyses and, therefore, we cannot confirm the causality hypothesis. However, the magnitude of the found associations is very strong and we should consider the potential role of the psoriasis itself on sexual dysfunction occurring in affected patients; 2) Sam- 
ple selection was not random, and the controls were healthy volunteers, thus raising the possibility of selection bias. Nevertheless, we matched them by age and sex to try and avoid a possible bias of control group. In fact, the frequency of sexual dysfunction in the psoriasis group is so high that the results could scarcely be explained by bias; 3 ) The study's sample size was limited, although it was sufficient to achieve a power higher than $80 \%$. So, the causal inferences should be viewed with caution due to the study design. A larger study with incident cases of psoriasis should be performed to comprehensively explore causality. Future research in the field of psoriasis and sexual dysfunction should investigate the linking factors between ASI lesions and sexual dysfunction, and which are the causes of dysfunction amongst the different components of the sexual response cycle. In addition, studies considering biological markers of systemic inflammation or imaging techniques such as dynamic penile color-duplex ultrasound are warranted.

\section{CONCLUSION}

In conclusion, we have found a high frequency of sexual dysfunction problems in psoriasis patients, and we have identified two potential independent factors involved in this relation: anxiety and/or depression and ASI lesions. We suggest that the assessment of sexual function should be a part of the comprehensive care of moderate to severe psoriasis patients. For this purpose, the MGH-SFQ is a useful and simple tool to be used in daily clinical practice. Screening and treatment of anxiety and depression, which are quite prevalent in this group of patients, should also be considered because clinical signs of these conditions can significantly impair sexual function. During physical examination, special attention should be paid to ASI involvement, which could be considered as a severity criterion in deciding treatment, since this involvement significantly and independently impairs sexual function.]

\section{ACKNOWLEDGEMENTS}

We wish to thank Ooopart Inc. (Granada, Spain) for providing data visualization.

\section{REFERENCE}

1. Parisi R, Symmons DP, Griffiths CE, Ashcroft DM; Identification and Management of Psoriasis and Associated ComorbidiTy (IMPACT) project team. Global epidemiology of psoriasis: a systematic review of incidence and prevalence. J Invest Dermatol. 2013;133:377-85.

2. Rapp SR, Feldman SR, Exum ML, Fleischer AB Jr, Reboussin DM. Psoriasis causes as much disability as other major medical diseases. J Am Acad Dermatol. 1999;41:401-7.

3. Dubertret L, Mrowietz U, Ranki A, van de Kerkhof PC, Chimenti S, Lotti T, et al. European patient perspectives on the impact of psoriasis: the EUROPSO patient membership survey. Br J Dermatol. 2006;155:729-36.

4. Palijan TZ, Kovacević D, Koić E, Ruzić K, Dervinja F. The impact of psoriasis on the quality of life and psychological characteristics of persons suffering from psoriasis. Coll Antropol. 2011;35:81-5.

5. Rieder E, Tausk F. Psoriasis, a model of dermatologic psychosomatic disease: psychiatric implications and treatments. Int J Dermatol. 2012;51:12-26.

6. Kimball AB, Jacobson C, Weiss S, Vreeland MG, Wu Y. The psychosocial burden of psoriasis. Am J Clin Dermatol. 2005;6:383-92.

7. van Dorssen IE, Boom BW, Hengeveld MW. Experience of sexuality in patients with psoriasis and constitutional eczema. Ned Tijdschr Geneeskd. 1992;136:2175-8.

8. Brumpton B, Langhammer A, Romundstad P, Chen Y, Mai XM. The associations of anxiety and depression symptoms with weight change and incident obesity: The HUNT Study. Int J Obes (Lond). 2013;37:1268-74.
9. Meeuwis KA, de Hullu JA, van de Nieuwenhof HP, Evers AW, Massuger LF, van de Kerkhof PC, et al. Quality of life and sexual health in patients with genital psoriasis. Br J Dermatol. 2011;164:1247-55.

10. Türel Ermertcan A, Temeltaş G, Deveci A, Dinç G, Güler HB, Oztürkcan S. Sexual dysfunction in patients with psoriasis. J Dermatol. 2006;33:772-8.

11. Guenther L, Han C, Szapary P, Schenkel B, Poulin Y, Bourcier M, et al. Impact of ustekinumab on health-related quality of life and sexual difficulties associated with psoriasis: results from two phase III clinical trials. J Eur Acad Dermatol Venereol. 2011;25:851-7.

12. Kurizky PS, Mota LM. Sexual dysfunction in patients with psoriasis and psoriatic arthritis--a systematic review. Rev Bras Reumatol. 2012;52:943-8.

13. Puig L, Bordas X, Carrascosa JM, Daudén E, Ferrándiz C, Hernanz JM, et al. Consensus document on the evaluation and treatment of moderate-to-severe psoriasis. Spanish psoriasis group of the Spanish Academy of Dermatology and Venereology. Actas Dermosifiliogr. 2009;100:277-86.

14. Robinson A, Kardos M, Kimball AB. Physician Global Assessment (PGA) and Psoriasis Area and Severity Index (PASI): why do both? A systematic analysis of randomized controlled trials of biologic agents for moderate to severe plaque psoriasis. J Am Acad Dermatol. 2012;66:369-75.

15. Labbate LA, Lare SB. Sexual dysfunction in male psychiatric outpatients: validity of the Massachusetts General Hospital Sexual Functioning Questionnaire. Psychother Psychosom. 2001;70:221-5. 
16. Sierra JC, Vallejo-Medina P, Santos-Iglesias P, Lameiras Fernández M. Validation of Massachusetts General Hospital-Sexual Functioning Questionnaire (MGH-SFQ) in a Spanish population. Aten Primaria. 2012;44:516-24.

17. Zigmond AS, Snaith RP. The hospital anxiety and depression scale. Acta Psychiatr Scand. 1983;67:361-70.

18. Navinés R, Castellví P, Moreno-España J, Gimenez D, Udina M, Cañizares S, et al. Depressive and anxiety disorders in chronic hepatitis $C$ patients: reliability and validity of the Patient Health Questionnaire. J Affect Disord. 2012;138:343-51.

19. Feldman SR, Fleischer AB Jr, Reboussin DM, Rapp SR, Exum ML, Clark AR, et al. The self-administered psoriasis area and severity index is valid and reliable. $J$ Invest Dermatol. 1996;106:183-6.

20. Derogatis LR, Burnett AL. The epidemiology of sexual dysfunctions. J Sex Med. 2008;5:289-300.

21. Derogatis LR. Clinical and research evaluations of sexual dysfunctions. Adv Psychosom Med. 2008;29:7-22.

22. Miettinen OS, Cook EF. Confounding: essence and detection. Am J Epidemiol. 1981;114:593-603

23. McMahon CG, Jannini E, Waldinger M, Rowland D. Standard operating procedures in the disorders of orgasm and ejaculation. J Sex Med. 2013;10:204-29.

24. Burri A, Greven C, Leupin M, Spector T, Rahman Q. A multivariate twin study of female sexual dysfunction. J Sex Med. 2012;9:2671-81.

25. Mercan S, Altunay IK, Demir B, Akpinar A, Kayaoglu S. Sexual dysfunctions in patients with neurodermatitis and psoriasis. J Sex Marital Ther. 2008;34:160-8.

26. Gupta MA, Gupta AK. Psoriasis and sex: a study of moderately to severely affected patients. Int J Dermatol. 1997;36:259-62.

27. Sampogna F, Gisondi P, Tabolli S, Abeni D; IDI Multipurpose Psoriasis Research on Vital Experiences investigators. Impairment of sexual life in patients with psoriasis. Dermatology. 2007;214:144-50.

28. Kurd SK, Troxel AB, Crits-Christoph P, Gelfand JM. The risk of depression, anxiety, and suicidality in patients with psoriasis: a population-based cohort study. Arch Dermatol. 2010;146:891-5.

29. Kalmbach DA, Ciesla JA, Janata JW, Kingsberg SA. Specificity of anhedonic depression and anxious arousal with sexual problems among sexually healthy young adults. J Sex Med. 2012;9:505-13.

30. Schmid-Ott G, Kuensebeck HW, Jaeger B, Werfel T, Frahm K, Ruitman J, et al. Validity study for the stigmatization experience in atopic dermatitis and psoriatic patients. Acta Derm Venereol. 1999;79:443-7.

31. Wolkenstein P. Living with psoriasis. J Eur Acad Dermatol Venereol. 2006;20:28-32

32. Rossen P, Pedersen AF, Zachariae R, von der Maase H. Sexuality and body image in long-term survivors of testicular cancer. Eur J Cancer. 2012;48:571-8.

33. Pauls RN, Occhino JA, Dryfhout VL. Effects of pregnancy on female sexual function and body image: a prospective study. J Sex Med. 2008;5:1915-22.

34. Nobre PJ, Pinto-Gouveia J. Cognitive and emotional predictors of female sexual dysfunctions: preliminary findings. J Sex Marital Ther. 2008;34:325-42.

35. Magin P, Heading G, Adams J, Pond D. Sex and the skin: a qualitative study of patients with acne, psoriasis and atopic eczema. Psychol Health Med. 2010;15:454-62.

36. Khoury LR, Danielsen PL, Skiveren J. Body image altered by psoriasis. A study based on individual interviews and a model for body image. J Dermatolog Treat. 2014;25:2-7

37. American Academy of Dermatology Work Group, Menter A, Korman NJ, Elmets CA, Feldman SR, Gelfand JM, et al. Guidelines of care for the management of psoriasis and psoriatic arthritis: section 6 . Guidelines of care for the treatment of psoriasis and psoriatic arthritis: case-based presentations and evidence-based conclusions. J Am Acad Dermatol. 2011;65:137-74.

38. Seikowski K, Gelbrich M, Harth W. Sexual self-reflection in patients with atopic dermatitis and psoriasis. Hautarzt. 2008;59:297-303.

39. Hrehorów E, Salomon J, Matusiak L, Reich A, Szepietowski JC. Patients with psoriasis feel stigmatized. Acta Derm Venereol. 2012;92:67-72.

40. Sanchez DT, Kiefer AK. Body concerns in and out of the bedroom: implications for sexual pleasure and problems. Arch Sex Behav. 2007;36:808-20.
M AILING ADDRESS:

A lejandro M olina Leyva

D epartment of D ermatology

U niversity H ospital, Granada.

A venida D octor Oloriz 16.

H ospital U niversitario San Cecilio.

18012 - Granada - Spain

E-mail:alejandromolinaleyva@gmail.com

How to cite this article: Molina-Leyva A, Almodovar-Real A, Ruiz-Carrascosa JC, Molina-Leyva I, Naranjo-Sintes $\mathrm{R}$, Jimenez-Moleon JJ. Distribution pattern of psoriasis, anxiety and depression as possible causes of sexual dysfunction in patients with moderate to severe psoriasis. An Bras Dermatol. 2015;90(3):338-45. 